This is the peer reviewed version of the following article:

Aleksić, S.O., Mitrović, N.S., Nikolić, Z., Luković, M.D., Obradović, N.N., Luković, S.G., 2019. Three-Axis' Heat Loss Anemometer Comprising Thick-Film Segmented Thermistors. IEEE Sensors Journal 19, 10228-10235.

https://doi.org/10.1109/JSEN.2019.2929356

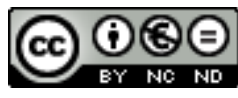

This work is licensed under a Creative Commons Attribution Non Commercial No Derivatives 4.0 license 


\title{
Three-axis' heat loss anemometer comprising thick-film segmented thermistors
}

\author{
Stanko O. Aleksic, Nebojsa S. Mitrovic, member IEEE, Zoran Nikolic, Miloljub D. Lukovic, \\ Nina N. Obradovic, Snezana G. Lukovic
}

\begin{abstract}
NTC thick-film segmented thermistors were used as anemometer sensing devices. They were screen printed of thickfilm thermistor paste based on modified $\mathrm{NiMn}_{2} \mathrm{O}_{4}$ fine powder, organic vehicle and glass frit. Their electrical properties such as resistance vs. temperature $R(T)$ and thermistor exponential factor $B$ were obtained using measurements in the climatic test chamber. An uniaxial anemometer was formed using a thickfilm segmented thermistor which was placed in the hole drilled in rectangular piece of thermally insulating material. The uniaxial anemometer was used for the optimization of operating point of segmented thermistors as self-heating / wind sensing devices. The DC supply voltage was correlated with the air temperature sub-ranges ( $\mathrm{RCV})$. The power save mode such as 30s self-heating/5 min pause was used to measure the thermistor response on stable wind blow. The three-axis' anemometer was formed using five sensor devices placed in five holes drilled in the cubical piece of thermally insulating material: three thermistor sensors measure wind speed on the $x, y, z-$ axes, the fourth sensor $P t \mathbf{1 0 0 0}$ measures the air temperature $T$, while the fifth sensor (capacitive type) measures humidity $H$. The obtained sensitivity and inaccuracy were compared with respective ones of other anemometers.
\end{abstract}

Index Terms - thick-film thermistors, heath loss anemometer

\section{INTRODUCTION}

A NEMOMETERS are devices for measuring the speed or pressure of the wind in meteorological stations, at the airports, windmill parks, agriculture, navy, sports, etc. Generally, they belong to one of three types related to the measuring directions: uniaxial, two-axis' (X-Y-type) and three-axis' (X,Y,Z-type). Many different types of anemometers were developed to operate on different principles such as cup, hot wire, windmill, pressure tube, ultrasonic, laser Doppler, elastic membranes, microphones, heat loss thermistor and many other anemometers. Our threeaxis' anemometer belongs to $\mathrm{X}, \mathrm{Y}, \mathrm{Z}$ - type and operates on the heat loss of thick film thermistors. The anemometer construction is given in Figure 1a.

\section{Manuscript received}

S. O. Aleksic and N. S. Mitrovic are with Faculty of Technical Sciences, University of Kragujevac, 32000 Cacak, Serbia (e-mail: frakulah@gmail. com, nebojsa.mitrovic@ftn.kg.ac.rs), Z. Nikolic is with Faculty of Physics, University of Belgrade, 11000 Belgrade, Serbia (e-mail: nizoran@ff.bg.ac. rs), N.N. Obradovic is with Institute of Technical Sciences-SASA, University of Belgrade, 11000 Belgrade, Serbia (e-mail: nina.obradovic@itn.sanu.ac.rs), M. D. Lukovic and S. G. Lukovic, are with Institute for Multidisciplinary Research - IMSI, University of Belgrade, 11030 Belgrade, Serbia (e-mail: lukovic@imsi.rs; snezana.lukovic@imsi.rs).

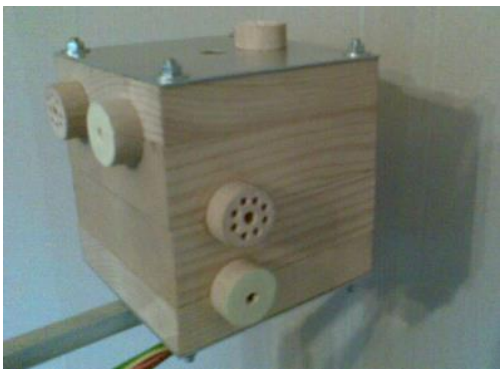

Figure 1a. Three-axis' heat loss anemometer (prototype) in thermally insulating (wooden) housing comprises NTC thick-film segmented thermistors: actual size $100 \cdot 100 \cdot 100 \mathrm{~mm}$

The constructions and main characteristics of commonly used types of anemometers are described in brief as follows: The cup-type anemometer consists of cups which rotate round the vertical axis when the wind presses against them. The number of revolutions per second is directly proportional to wind speed. The cup anemometers are used worldwide in meteorology [1-2]. The hot wire is a heat loss anemometer and it measures wind speed and pressure: hot wire cools when the wind blows over it. A relationship can be obtained between the resistance of the wire and the air flow speed. It also measures the air volume flow in the ducts of air conditioning equipment [3-5]. The windmill anemometers measure wind speed and wind flow direction. When the wind blows it presses a small propeller: the number of revolutions per second is directly proportional to wind speed [6-7]. The pressure tube is windsock and it only provides indication of the wind direction at airports. The faster the wind blows the higher sock raises off the ground [8]. The ultrasonic anemometers send sonic pulses from transmitter to the receiver, which is placed on $0.5 \mathrm{~m}$ distance for example. The higher wind speed causes higher disruption of the stream of pulses. $[9,10]$. The laser Doppler anemometer utilizes the Doppler effect to determine the flow of the air. Actually, a laser beam is split into two halves: one is propagated out of the instrument and another is closed in the instrument as a referent beam. A shift between two beams is directly proportional to wind speed [11,12]. Pitot tube, elastic membranes under wind pressures and microphones are often used for wind speed measuring [13-15]. The anemometers comprising disk thermistors (PTC or NTC) are heat loss sensors; they change the resistance when the wind blows and cools them. They are also used for the gas volume measurements in the pipes $[16,17]$. 
The experiments with thick-film segmented thermistors as self-heating/sensing devices and air flow measurements have started more than ten years ago (2004-2006) [18,19]. After the promising results, ten years pause occurred. A few years ago a new NTC thermistor paste was developed (based on modified $\mathrm{NiMn}_{2} \mathrm{O}_{4}$ ): the sheet resistivity was lowered a few times, while the size of segmented thermistors where reduced two times [20]. After that, the new NTC thick-film segmented thermistors with reduced dimensions were used for thermal flowmeter for water based on heat loss principle [21]. In that period, the idea emerged to construct the heat loss uniaxial and three-axis' anemometers. In the first step of the optimization and analysis the objective was to measure wind velocity as a vector only for stable winds in moderate climate conditions.

\section{NTC THICK- FILM SEgMENTED THERMISTORS}

The construction of NTC thick-film segmented thermistor with reduced dimensions is given in Figure 1b. It consists of two PdAg layers acting as electrodes, and NTC layer between them. The resistance vs. temperature of segmented thermistor was measured in climatic test chamber (Heraeus-Wötsch VK I 08/450, recalibrated by Pt-1000) and given in Figure 2.

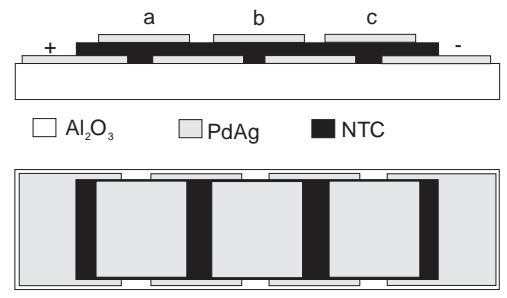

Figure 1b. NTC thick-film segmented thermistor printed on alumina: cross section (up) and top view (down). PdAg-electrodes in a zig-zag order, NTCthick- film thermistor layer, $\mathrm{Al}_{2} \mathrm{O}_{3}$-alumina substrate. "+, -" power supply electrodes, a,b,c- inner electrodes.

The thermistor segmented construction with the inner electrodes enables measuring of the temperature gradient on self-heating thermistor and determination of the wind flow direction (back or forward).

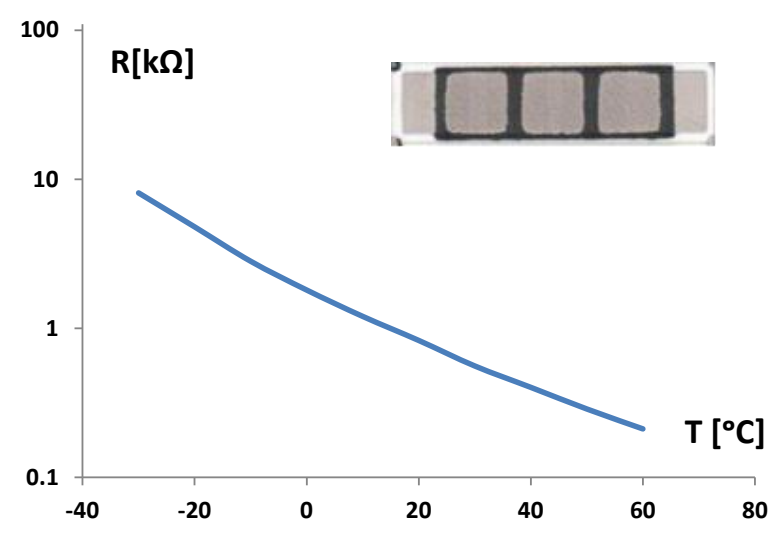

Figure 2. NTC thick-film segmented thermistor with reduced dimensions- top view (insert photo) and it's DC resistance R vs. temperature T ( measured in the climatic test chamber). Alumina substrate: $25.4 \cdot 6.35 \cdot 0.5 \mathrm{~mm}$.
Thick-film segmented thermistors were printed using a custom designed thermistor paste based on fine nanosized powder $\mathrm{Cu}_{0.2} \mathrm{Ni}_{0.5} \mathrm{Zn}_{1.0} \mathrm{Mn}_{1.3} \mathrm{O}_{4}$ (modified $\mathrm{NiMn}_{2} \mathrm{O}_{4}$ ), organic vehicle and glass frit. The dried samples were sintered in conveyor furnace in the air at $850^{\circ} \mathrm{C} / 10 \mathrm{~min}$. The thermistor resistance $\mathrm{R}(\mathrm{T})$ given in Figure 2 can be described by Steinhart-Hart equation [22]:

$$
R(T)=A \exp \left[\frac{B}{T}+\frac{C}{T^{2}}+\frac{D}{T^{3}}\right] \ldots \ldots \ldots
$$

where A,B,C,D are constants experimentally determined and $\mathrm{T}$ is a temperature in $\mathrm{K}$. Using the approximation of equation (1) to the first article $(B / T)$ and thermistor values $R_{1}$ and $R_{2}$ measured at temperature $T_{1}$ and $T_{2}$ exponential factor $B$ can be determined by following equation :

$$
B=\left[\frac{T_{1} \cdot T_{2}}{T_{2}-T_{1}}\right] \cdot \ln \left[\frac{R_{1}}{R_{2}}\right] \ldots \ldots \ldots .
$$

Finally, for some measured thermistor resistance $R_{x}$, the unknown temperature $T_{x}$ can be calculated using rearranged equation:

$$
T_{x}=B \cdot T_{0} /\left[B+T_{0} \ln \left(\frac{R_{x}}{R_{0}}\right)\right] \ldots \ldots \ldots
$$

$\mathrm{R}_{0}$ is thermistor nominal resistance (measured at room temperature $\mathrm{T}_{0}=293.16 \mathrm{~K}$ ), and $\mathrm{B}$ is thermistor exponential factor obtained by equation (2). In our case, nominal resistance $\mathrm{R}_{0}$ measured at $20^{\circ} \mathrm{C}$ was $\mathrm{R}_{20}=828.5 \Omega$ and thermistor exponential factor was calculated by equation (2) as $\mathrm{B}_{10-30^{\circ} \mathrm{C}}=3356 \mathrm{~K}$.

In the beginning of our experiments, the air temperature $\mathrm{T}$ was measured using segmented thermistor and equation (3), while platinum thermometer Pt 1000 was used as a referent. Before the uniaxial anemometer was formed only the Pt 1000 results were taken into account as they were more stable and more accurate for the air temperature measurements (resolution $0.01^{\circ} \mathrm{C}$; inaccuracy $\pm 0.025^{\circ} \mathrm{C}$ ).

\section{Uniaxial Anemometer Based on Segmented Thermistors}

The uniaxial heat loss anemometer construction is given in Figure 3. It consists of a thick-film segmented thermistor placed axially in the cylindrical hole (tube) drilled in the rectangular piece of thermally insulating material (wood).
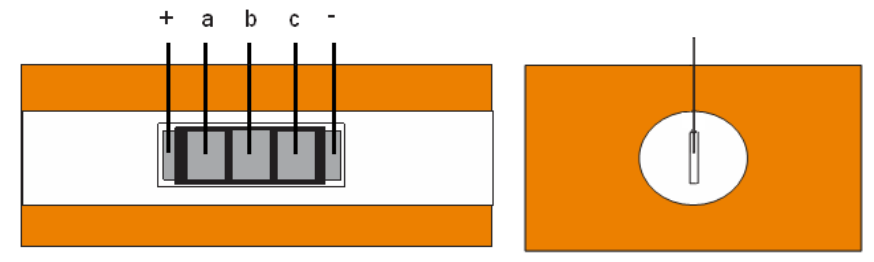

Figure 3. The uniaxial heat loss anemometer construction: NTC thick-film segmented thermistor placed along the main axis. Longitudinal cross section (right), and transversal cross section (left). 
The wooden housing actual size was $100 \cdot 80 \cdot 50 \mathrm{~mm}$, while drilled hole had $20 \mathrm{~mm}$ in diameter. The uniaxial anemometer given in Figure 3 was used for analysis and optimization of operating point and measuring wind velocity.

\section{A. Static characteristics of uniaxial anemometer}

The uniaxial anemometer set up electrical scheme is given in Figure 4. The device operates in the power save mode e.g. impulse switching regime: "switched on" power supply (selfheating period) lasts $30 \mathrm{~s}$ and after that period the power supply is "switched off" - pause lasts 5 min (natural cooling period to the initial state). The anemometer output (response) was self-heating current $\mathrm{I}_{30}$ measured in the $30^{\text {th }}$ second (before "power switched off") using Fluke 179 multimeter and "hold max".

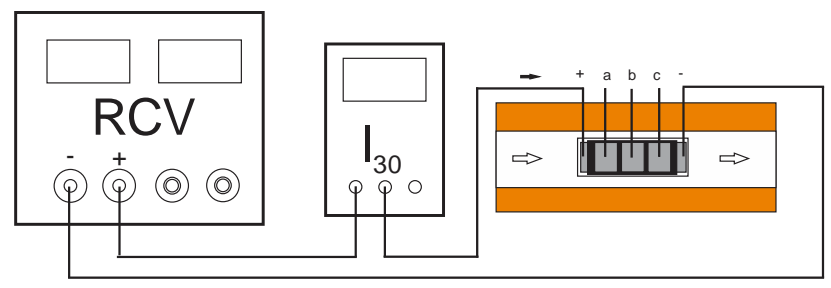

Figure 4. Uniaxial anemometer set up : RCV-power supply, $\mathrm{I}_{30}$ self-heating current measured by multimeter, thick-film segmented thermistor in the tube, white arrows indicate the direction of the wind.

The static characteristics of the uniaxial anemometer were measured in the absence of the air flow (wind) in the same climatic test chamber ( Heraeus-Wötsch VK I 08/450 recalibrated in the range -20 to $40^{\circ} \mathrm{C}$ to less than $0.025^{\circ} \mathrm{C}$ of inaccuracy by using platinum termometer Pt 1000, Iskra) . The main output electrodes of the thermistor "+" and "-" were connected to the output of adaptive DC power supply called RCV (HQ PowerTM PS-3003). The output voltage U from RCV power supply (Range Constant Voltage) is fixed in the temperature range of $\Delta \mathrm{T}=10^{\circ} \mathrm{C}$. Actually, the power supply voltage $\mathrm{U}$ is decreased in steps of 2 to $5 \mathrm{~V} / 10^{\circ} \mathrm{C}$ in the air temperature range from $-20^{\circ} \mathrm{C}$ up to $+40^{\circ} \mathrm{C}$, as given in Figure 5. RCV for sub-ranges of $10^{\circ} \mathrm{C}$ have a "trend-line" or dashed curve.

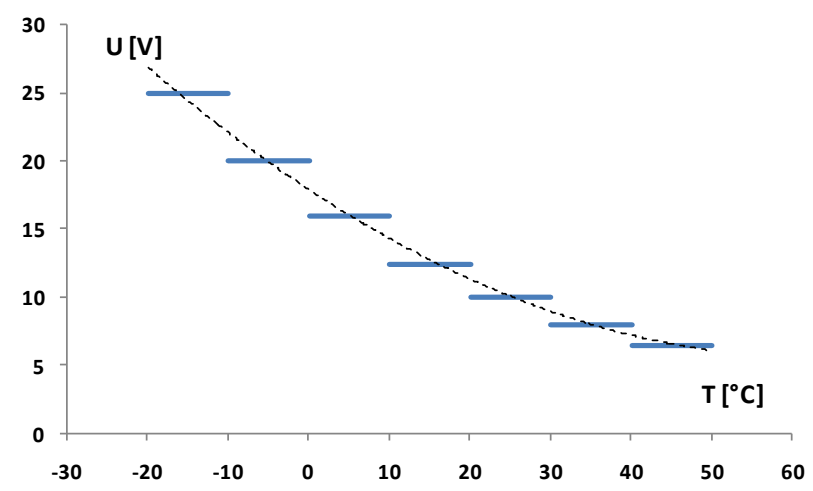

Figure 5. Optimization of adaptive DC power supply: RCV-range constant voltage $\mathrm{U}$ in steps vs. air temperature T, trend-line curve - - - (dashed line).
The criteria for selection of RCV voltages was self-heating current of the thermistor $\mathrm{I}_{30}$ : value $\mathrm{I}_{30 \text { max }}$ to be 15 to $25 \mathrm{~mA}$ in the range from -20 to $40{ }^{\circ} \mathrm{C}$ and in the sub-ranges of $10^{\circ} \mathrm{C}$ to have $\mathrm{I}_{30 \mathrm{max}}-\mathrm{I}_{30 \mathrm{~min}} \approx 10 \mathrm{~mA}$ or for example (around $1 \mathrm{~mA} / 1^{\circ} \mathrm{C}$ ). RCV power supply enables the limited change of $\mathrm{I}_{30}$ self-heating thermistor current in the absence of air flow (wind). $\mathrm{RCV}$ voltage $\mathrm{U}$ is lowered down each $\Delta \mathrm{T}=10^{\circ} \mathrm{C}$ of air temperature increase to adapt the self-heating power related to $\mathrm{RCV}$ (moves back the operating point of $\mathrm{I}_{30}$ from local maximum to next local minimum), as given in Figure 6. Each $10^{\circ} \mathrm{C}$ the next voltage is changed manually. The self-heating current increases because the NTC thermistor raises the selftemperature and lowers resistance. After period of 30 s of selfheating, the thermistor self-temperature is round $5-10^{\circ} \mathrm{C}$ higher from the air temperature outside (for example), which is required for the heat loss principle.

The deviation (instability) of RCV chopper power supply was less than $10 \mathrm{mV}$ and measured noise round $5 \mathrm{mV}$ peak to peak in the whole $\mathrm{RCV}$ range.

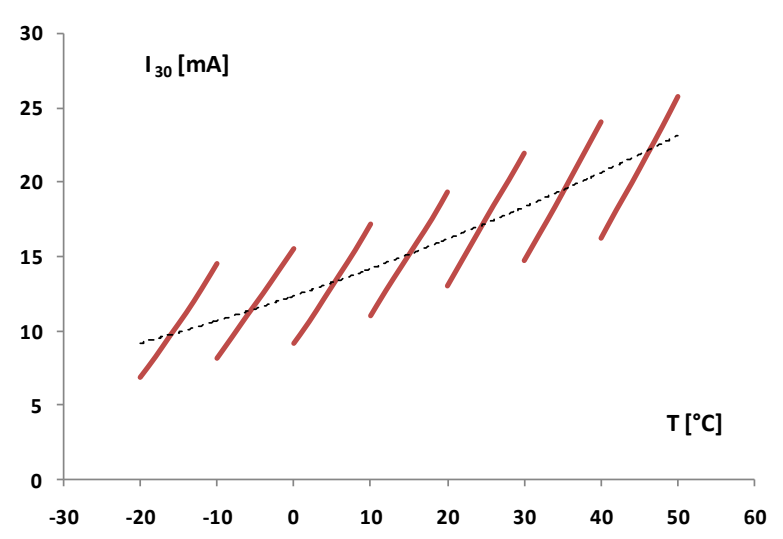

Figure 6. Uniaxial anemometer operating point: self-heating current $I_{30}$ as a function of temperature $\mathrm{T}$ in the absence of air flow: adaptive RCV power supply voltage U was used as a parameter. Trend-line curve - - - (dashed line).

The self-heating process of the thermistor in the housing depends on the static heat loss in the absence of air flow. The power save mode e.g., self-heating period / natural cooling period (30s / $5 \mathrm{~min}$ ) was chosen as the thermistor self-heating power is low $(0.1-0.6 \mathrm{~W})$ and $30 \mathrm{~s}$ is needed for $\mathrm{I}_{30}$ to reach the stable value after "switch on". The maximum thermistor power dissipation $\mathrm{P}=\mathrm{U} \cdot \mathrm{I}_{30}$ can be calculated using the results given in Figures 5 and 6 . The maximum of power dissipation calculated from Figure 6 in the whole measuring range varies from 0.5 to $0.25 \mathrm{~W}$ depending on RCV.

\section{B. Uniaxial anemometer response to stable winds}

The anemometer response $I_{30}$ to stable wind velocity $\mathrm{v}$ at different air temperature $\mathrm{T}$ as parameter was measured using the set up scheme given in Figure 4. The stable winds were produced using small propeller driven by AC voltage regulator. The wind from propeller was directed to the channel with embedded thermistor sensor using a short cardboard tube with honeycomb filter (air collimator). The wind velocities were measured using propeller type digital 
anemometer EA 3010 Techno-line as an independent sensor (velocity range $0.2-30 \mathrm{~m} / \mathrm{s}$, inaccuracy $3 \%$, declared by producer; recalibrated in the range $0.5-5 \mathrm{~m} / \mathrm{s}$ to inaccuracy of $1 \%$, using cup-type anemometer Vector A100LK ). For example, the uniaxial anemometer responses $\mathrm{I}_{30}$ to wind blow velocities $(v=0-8 \mathrm{~m} / \mathrm{s})$ are given in Figure $7(\mathrm{a}, \mathrm{b}, \mathrm{c}, \mathrm{d})$.
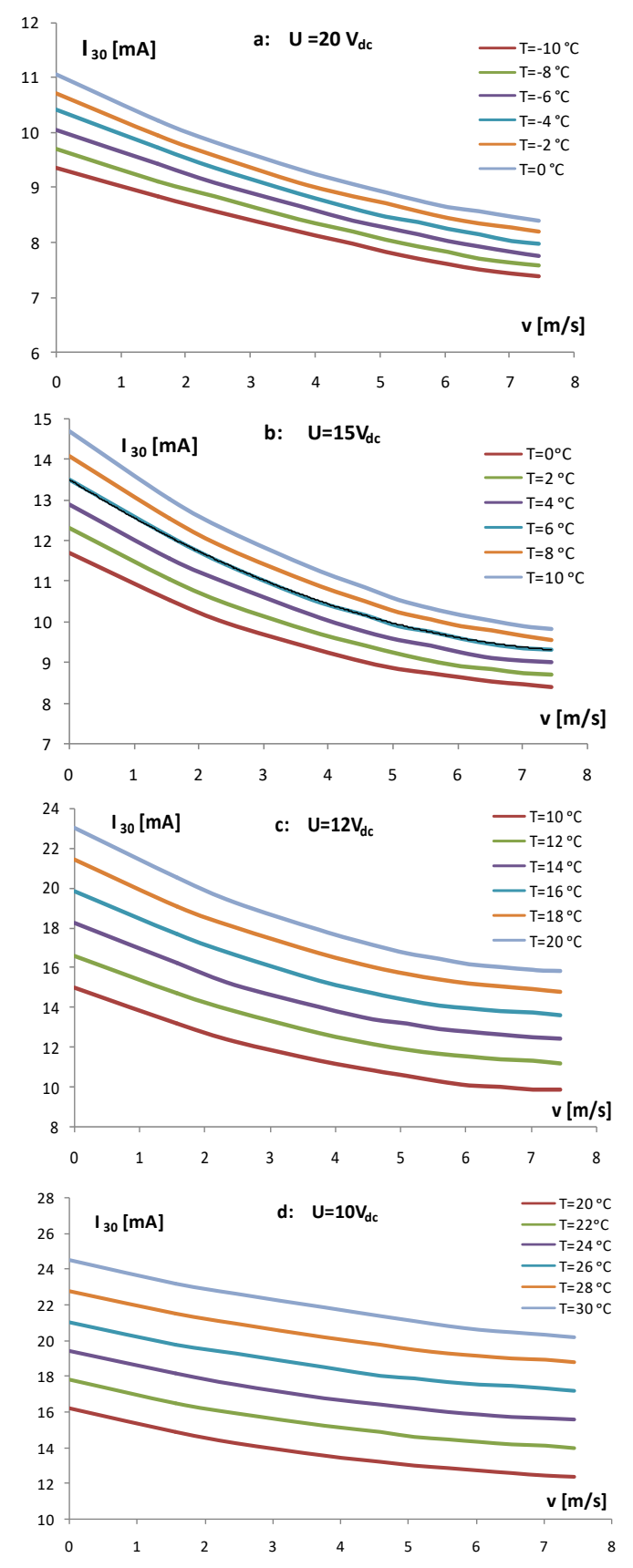

Figure 7. The uniaxial anemometer response: self-heating current $I_{30}$ vs. wind velocity $\mathrm{v}$ (calibration curves). The air temperatures in climatic test chamber $\mathrm{T}$ and $\mathrm{RCV}$ power supply voltages $\mathrm{U}_{\mathrm{dc}}$ were used as parameters: a- $\left[(-10,0)^{\circ} \mathrm{C}, 20\right.$ $\left.\mathrm{V}_{\mathrm{dc}}\right], \mathrm{b}-\left[(0,10){ }^{\circ} \mathrm{C}, 15 \mathrm{~V}_{\mathrm{dc}}\right], \mathrm{c}-\left[(10,20){ }^{\circ} \mathrm{C}, 12 \mathrm{~V}_{\mathrm{dc}}\right], \mathrm{d}-\left[(20,30){ }^{\circ} \mathrm{C}, 10 \mathrm{~V}_{\mathrm{dc}}\right]$.

The air temperature $\mathrm{T}$ in the sub-ranges such as $(-10,0)$, $(0,10),(10,20),(20,30){ }^{\circ} \mathrm{C}$ and corresponding RCV supply voltages $\mathrm{U}=20,15,12,10 \mathrm{~V}_{\mathrm{dc}}$, respectively, were changed as parameters. These curves represent the main calibration curves measured experimentally each $2^{\circ} \mathrm{C}$ of the ambient temperature; the other curves can be interpolated between the main calibration curves as auxiliary curves each $0.1^{\circ} \mathrm{C}$ or less, for example. The wind blow causes the voltage gradient on the segmented thermistor on inner electrodes a,b,c (see Figure 3 ) and indicates the flow direction: if $\Delta \mathrm{U}=\mathrm{U}_{\mathrm{ab}}-\mathrm{U}_{\mathrm{bc}}<0$ the wind direction is from left to right, and if $\Delta \mathrm{U}>0$ the wind blows in opposite direction. The influence of the air humidity $\mathrm{H}$ on the anemometer response $\mathrm{I}_{30}$ in the climatic test chamber was observed at $\mathrm{T}=20^{\circ} \mathrm{C}$ in the same range of wind velocity. For example, the humidity in the climatic chamber was changed from $40 \%$ to $60 \%$ and $80 \% \mathrm{RH}$, while thermistor current $\mathrm{I}_{30}$ change was less than $\pm 2 \%$ comparing to $\mathrm{I}_{30}$ at $60 \% \mathrm{RH}$ (near room humidity).

\section{Uniaxial anemometer response to angle of the wind blow}

In the experiments given above the anemometer hole with thermistor (see Figure 3) was fully opened and wind direction angle $\alpha$ to the main axis was zero. However, the wind blows often on some angle $\alpha$ with respect to main axis and anemometer response $\mathrm{I}_{30}$ depends on angle $\alpha$ value (Figure 8).
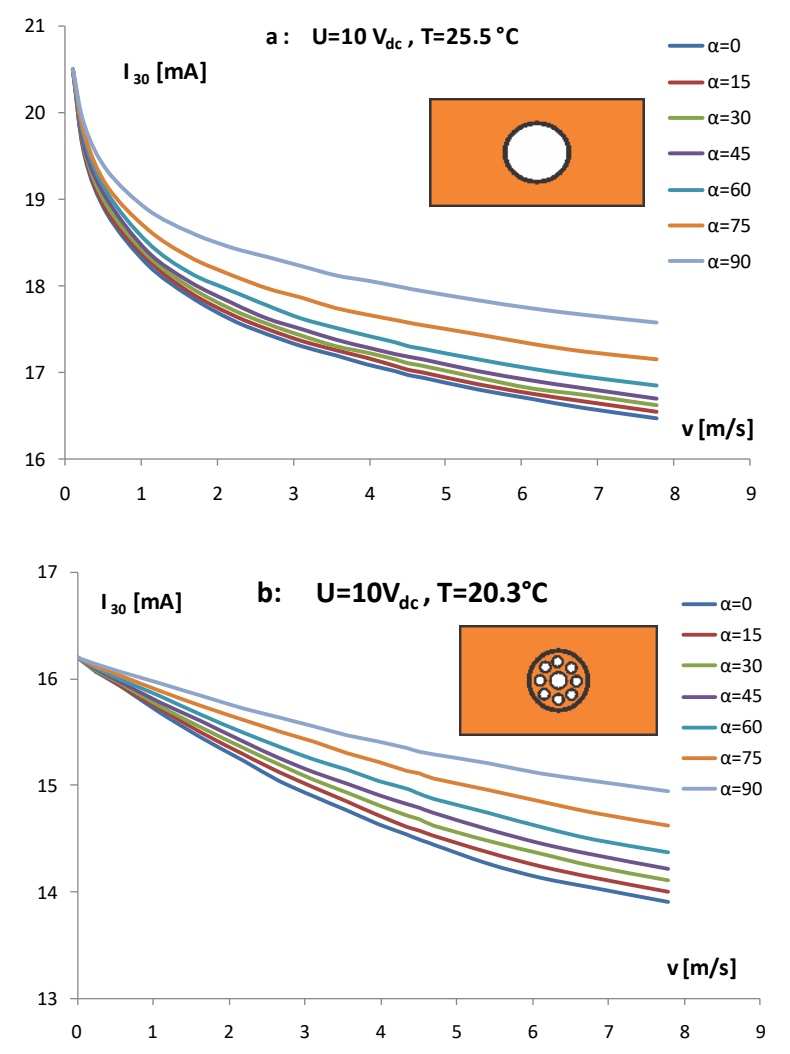

Figure 8. The uniaxial anemometer response: self-heating current $I_{30}$ as a function of wind angle $\alpha$. The air temperature $\mathrm{T}$ and RCV supply voltage $\mathrm{U}_{\mathrm{dc}}$ were used as parameters. a- large opening $\mathrm{f}=20 \mathrm{~mm}$, b- with reductor (central hole $\mathrm{f}=6 \mathrm{~mm}$ and 8 holes $\mathrm{f}=3 \mathrm{~mm}$, reductor length $18 \mathrm{~mm}$ ).

In the case with large hole openings such as $\mathrm{f}=20 \mathrm{~mm}$ the influence of wind blow angle $\alpha$ to dispersion of $I_{30}$ is smaller, compared with the case when the air flow reductors are placed on the front and back side of the anemometer hole. 
The dispersion of $\mathrm{I}_{30}$ was measured in both cases (fully opened hole and hole with reductors) at room temperatures and room humidity and at the same range of wind velocities. The responses $I_{30}$ on angle $\alpha$ from $\alpha=0^{\circ}$ to $\alpha=90^{\circ}$ in the steps of 15 degrees are given above in Figure $8 \mathrm{a}$ and $\mathrm{b}$. In the case of $\alpha=90^{\circ}$ there is no direct air flow through the anemometer channel but there is heat exchange between the inner and outside air. When the channel is closed by cork stopper the response curve to wind is almost horizontal.

The reductor with holes (Figure $8 \mathrm{~b}$ ) reduces the air flow 4 times (lowers the cooling of self-heating thermistor) and expands the measuring wind range for 4 times. Their slope in Figure $8 \mathrm{~b}$ is moderate comparing to logarithmic slope in Figure 8a. The use of reductors (Figure 8b) also enables relatively larger dispersion of response $\mathrm{I}_{30}$ on the wind angles $\alpha$. The results obtained were used for angle detection in twoaxis' and three-axis' anemometer systems.

\section{ThreE-AXIS' ANEMOMETER BASED ON SEGMENTED THERMISTORS}

The new three-axis' anemometer was formed using 3 uniaxial anemometers with reductors placed along the perpendicular axes of the coordinate system X,Y,Z (Figure 9). The air temperature sensor $\mathbf{T}$ was platinum probe $\mathrm{Pt} 1000$, Iskra, encapsulated in metal cylinder around $8 \mathrm{~mm}$ in diameter and $50 \mathrm{~mm}$ in length (resolution $0.01^{\circ} \mathrm{C}$; inaccuracy $\left.\pm 0.025^{\circ} \mathrm{C}\right)$. The humidity sensor $\mathbf{H}$ was HDC 2080 EVM (USB-stick, $15 \cdot 6.35 \cdot 37 \mathrm{~mm}$ ), Texas Instruments, RH-range $20-80 \%$ and inaccuracy $2 \%$. All the five sensors were placed in the holes drilled in cube of thermally insulating material (wooden housing).

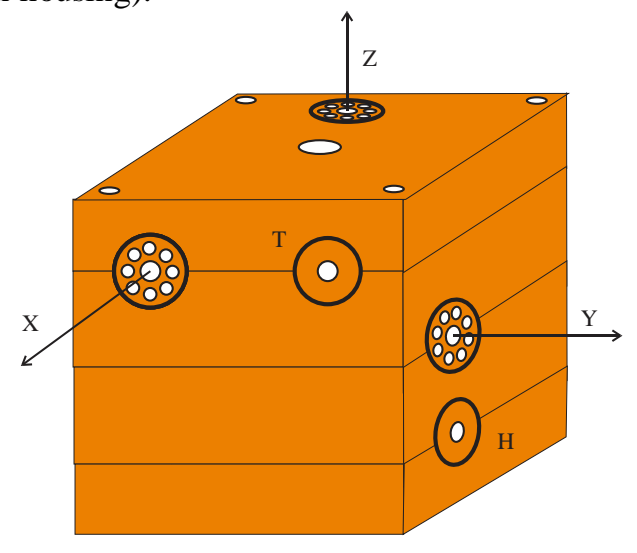

Figure 9. Three-axis' anemometer construction: wind speed sensors - X,Y, Z; Tair temperature sensor; $\mathrm{H}$ - humidity sensor. The housing made of cube of thermally insulating material (wood) - actual size $100 \cdot 100 \cdot 100 \mathrm{~mm}$. Holes diameter $\mathrm{f}=20 \mathrm{~mm}$. Air flow reductors placed on $\mathrm{X}, \mathrm{Y}, \mathrm{Z}$ channels.

\section{A. Three-axis' anemometer response to winds in $X$-Y plane}

Very often there is no wind in $\mathrm{Z}$ - vertical direction on horizontal flat terrains; voltage gradient measured on internal electrodes of thermistor $\Delta \mathrm{U}_{\mathrm{z}}=\mathrm{U}_{\mathrm{ab}}-\mathrm{U}_{\mathrm{bc}}=0$ e.g. the wind angles $\alpha_{z x}=\alpha_{z y}=90^{\circ}$. In this case the wind velocity can be determined from calibration curves for Z-axis as in Figure 10.

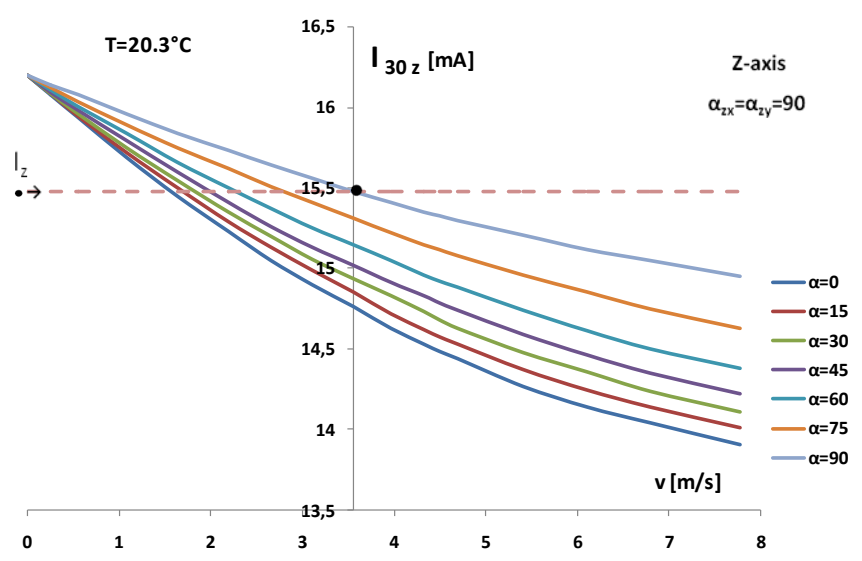

Figure 10. Three-axis' anemometer on flat terrain: the measured value $I_{z}$ and dashed line crosses the calibration curve $I_{30 z}$ for $\alpha_{z}=90$ degrees (bold point), the wind velocity on the horizontal axis is $\mathrm{v}=3.55 \mathrm{~m} / \mathrm{s}$. T- the air temperature.

The other responses to wind are measured on $\mathrm{X}$ and $\mathrm{Y}$ thermistor sensors as $\mathrm{I}_{30 \mathrm{x}}$ and $\mathrm{I}_{30 \mathrm{y}}$. As thermistor sensors $\mathrm{X}$ and $\mathrm{Y}$ are in rectangular coordinate system the angles to wind direction $\alpha_{\mathrm{x}}=90^{\circ}-\alpha_{\mathrm{y}}$ : the responses are symmetrical e.g. $\mathrm{I}_{30}$ $\left(\alpha_{\mathrm{x}}\right)=\mathrm{I}_{30}\left(-\alpha_{\mathrm{x}}\right)$ and $\mathrm{I}_{30}\left(\alpha_{\mathrm{y}}\right)=\mathrm{I}_{30}\left(-\alpha_{\mathrm{y}}\right)$. Practically, the wind angle $(\alpha)$ changes from 0 to \pm 45 degrees to the both axes. The wind direction $( \pm)$ along the $\mathrm{X}$ and $\mathrm{Y}$ wind sensors are also detected by voltage gradient $\Delta \mathrm{U}=\mathrm{U}_{\mathrm{ab}}-\mathrm{U}_{\mathrm{bc}}$ in the same way as given above in Section III $\mathrm{C}$ for the uniaxial anemometer. The calibration curves of $\mathrm{X}$ and $\mathrm{Y}$ wind sensors gave very similar $I_{30}$ dispersion for the wind angles $\alpha$ during sensor calibration, so as $\mathrm{I}_{30 \mathrm{x}}$ and $\mathrm{I}_{30 \mathrm{y}}$ can be directly compared as given in Figure 11 for two examples of $\alpha_{x}, \alpha_{y}$ values 45;45 and $0 ; 90$, respectively.

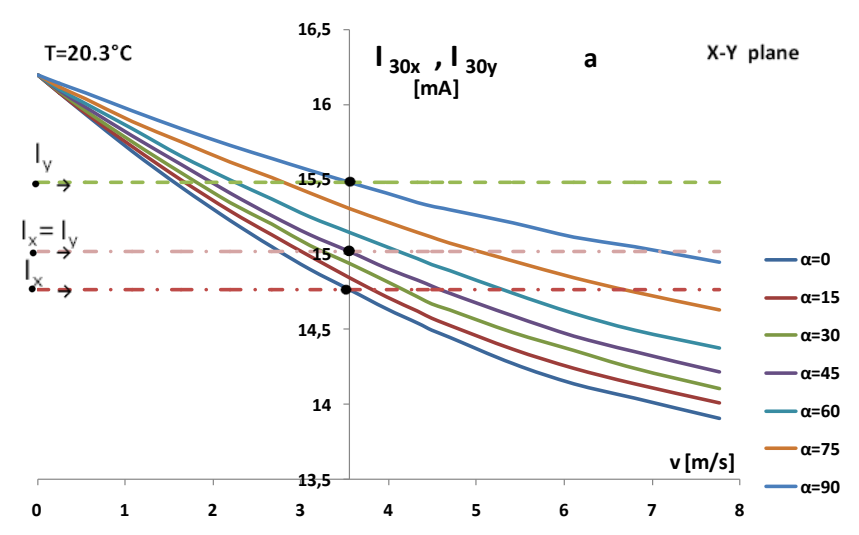

Figure 11. Three-axis' anemometer on flat terrain: the measured values Ix and Iy (points) and dashed lines cross the calibration curves $\mathrm{I}_{30 \mathrm{x}}$ and $\mathrm{I}_{30 \mathrm{y}}$ (bold points), the wind velocity on the horizontal axis is $v=3.55 \mathrm{~m} / \mathrm{s}$ for the pairs of $\alpha_{\mathrm{x}}, \alpha_{\mathrm{y}}$ values, 45;45 (Ix=Iy) and 0;90 respectively. T- the air temperature.

In the Figure 11 the results measured by three-axis' anemometer are given as currents values $\mathrm{I}_{\mathrm{x}}$ and $\mathrm{I}_{\mathrm{y}}$ (points) and dashed horizontal lines cross $\mathrm{X}$ and $\mathrm{Y}$ calibration curves at angles $\alpha_{\mathrm{x}}$ and $\alpha_{\mathrm{y}}$ (bold points). It is evident in Figure 11 that for $I_{y}>I_{x}$ angle values $\alpha_{y}>\alpha_{x}$. Also if $I_{y}=I_{x}$, it implies $\alpha_{y}$ 
$=\alpha_{x}=45^{\circ}$. From the same diagram (11) it can be noticed the only common solution (at bold point) for $\alpha_{y}=\alpha_{x}=45^{\circ}$ is the wind velocity $\mathrm{v}=3.55 \mathrm{~m} / \mathrm{s}$. Moreover, for the measured values $I_{y}>I_{x}$ in Figure 11, the common solution (at bold points) is also wind velocity $\mathrm{v}=3.55 \mathrm{~m} / \mathrm{s}$ and angle values are $\alpha_{x}=0^{\circ}$, $\alpha_{\mathrm{y}}=90^{\circ}$.

\section{B. Three-axis' anemometer response to wind in $X, Y, Z$ space}

On terrains with slope relative to vertical $\mathrm{Z}$ axis, for example $\alpha_{\mathrm{zx}}=\alpha_{\mathrm{zy}}=60^{\circ}$, the responses on $\mathrm{X}$ and $\mathrm{Y}$ thermistors depend on slope of the terrain. It implies measurement of the new calibration curves $\mathrm{I}_{30 \mathrm{x}}, \mathrm{I}_{30 \mathrm{y}}$ in $\mathrm{X}-\mathrm{Y}$ plain vs. wind velocity $\mathrm{v}$ and angle $\alpha_{\mathrm{z}}$. The wind velocity $\mathrm{v}$ and angles $\alpha_{\mathrm{x}}, \alpha_{\mathrm{y}}$ where obtained using the same procedure as above (Section IV A) and given in Figure $12 \mathrm{a}$ and $\mathrm{b}$ respectively.

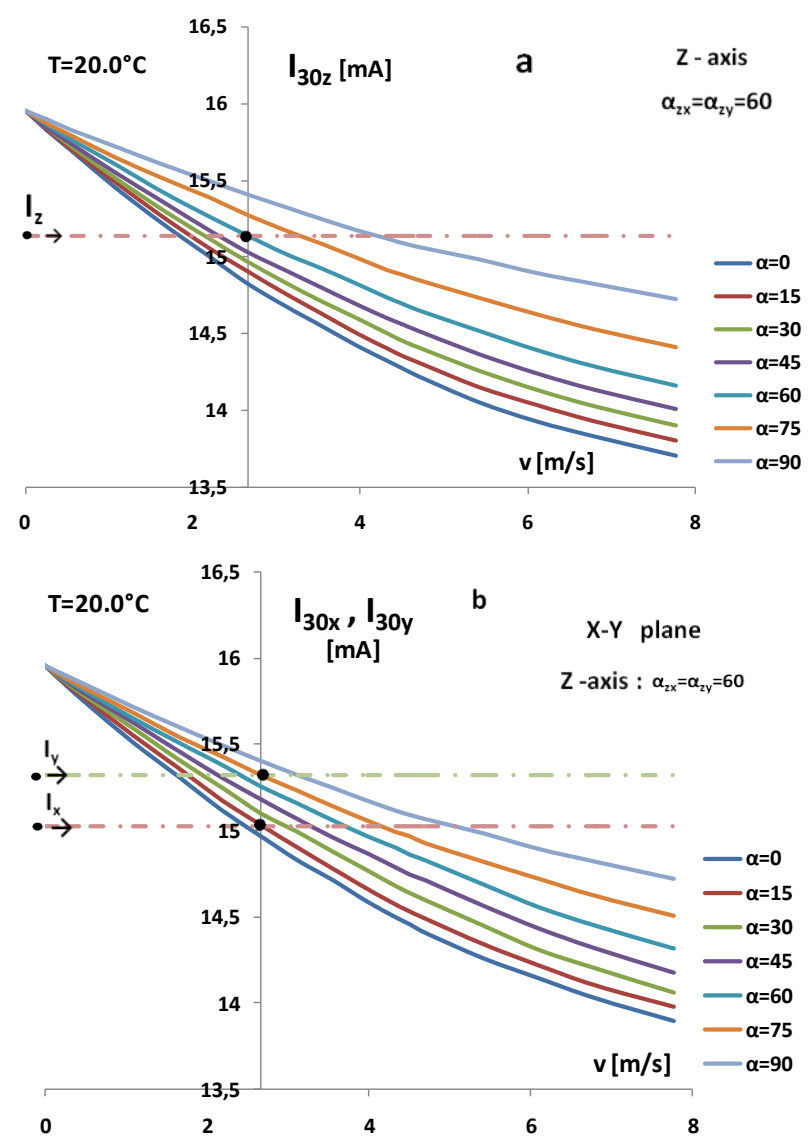

Figure 12. Three-axis' anemometer on sloping terrain; a. measured value Iz and dashed lines cross the calibration curves $\mathrm{I}_{30 \mathrm{z}}$ at bold point $\mathrm{v}=2.66 \mathrm{~m} / \mathrm{s}$ and at the angle $\alpha_{z x}=\alpha_{z y}=60$, b. Ix, Iy, cross new calibration curves $I_{30 x}$ and $I_{30 y}$ $\left(\alpha_{z x}=\alpha_{z y}=60\right)$ at bold points $v=2.66 \mathrm{~m} / \mathrm{s}$ and $\alpha_{x}=15, \alpha_{y}=75$ degrees.

The wind angles $(\alpha)$ are determined using the common solution - bold points on vertical axis in Figure 12. The air temperature $\mathrm{T}$ was used as a parameter. The new calibration curves $I_{30 x}, I_{30 y}$ in X-Y plain for $\alpha_{z x}=\alpha_{z y}=60^{\circ}$ differ from calibration curves in Figure 10 and 11 due to the terrain slope (angle $\alpha_{\mathrm{z}} \neq 90^{\circ}$ of $\mathrm{Z}$ axis), which additionally lowers the air flow trough $\mathrm{X}$ and $\mathrm{Y}$ thermistor sensor. Actually, angle $\alpha_{z} \neq 90^{\circ} \quad$ causes a little lower cooling of $\mathrm{X}$ and $\mathrm{Y}$ thermistor sensors and consequently a little higher sensor currents $\mathrm{I}_{30 \mathrm{x}}$ and $\mathrm{I}_{30 \mathrm{y}}$ in comparison with previous case (Section IV A). Other values for the slope of terrain such as $\alpha_{z}=75^{\circ}$ and $\alpha_{z}$ $=45^{\circ}$, for example, result in similar effects in comparison to slope $\alpha_{z}=60^{\circ}$ as described above. The measured calibration curves given in Figure 12 for $\mathrm{X}, \mathrm{Y}, \mathrm{Z}$ thermistor the wind sensors also depend on air temperature $\mathrm{T}$ as a parameter.

Out of the climatic test chamber the air temperature $\mathrm{T}$ can be stable within $0.025^{\circ} \mathrm{C}$ in the large room with concrete floor and thermal contact with the ground. The suitable time is early in the morning from 5-7h (for example beginning of October when the weather is stable). These conditions in the laboratory room were suitable for generating winds for measurements by three-axis' heat loss anemometer. Most of the measurements for uniaxial and three-axis' anemometer were performed in the Climatic-mechanic test laboratory of the IRITEL Institute. The measurements in real conditions outside the laboratory were performed on open area, on the flat terrain (meadow) and obtained results were in agreement with the results from laboratory measurements. The main problem in moderate climatic region as central Balkan is the absence of wind or presence of lot of weak winds (less than 2$5 \mathrm{~m} / \mathrm{s}$ ). The high-velocity wind Kosava (up to $10-30 \mathrm{~m} / \mathrm{s}$ ) blows a few times in November and March, rarely out of these periods. The measurements in real conditions on large plain fields are related to long term measurements with full electronic automation by using digital acquisition card (DAC) and software which is in preparation. The development of a smart heat-loss anemometer is expected as continued work in the near future.

\section{Discussion}

The presented novel anemometer named three-axis' heat loss anemometer, with range constant voltages (RCV) and selfheating thermistor operating in 30 s cycle, speaking strictly, is a complex type and do not belongs to only one group (constant current, constant voltage, constant temperature, impulse work) : it can be classified as constant voltage with principle / periodic (cycle) operation.

The operating point of uniaxial anemometer is optimized using RCV voltages for different air temperature sub-ranges (Figures 5 and 6). The power save mode e.g. impulse switching operating regime 30s heating / 5 min cooling was chosen to get higher sensitivity, repeatability and reliability. The use of reductors increases the measuring range several times. The uniaxial anemometer calibration curves $I_{30}$ as a function of wind velocity $\mathrm{v}$ and the air temperature $\mathrm{T}$ were measured in the large and temperature stable climatic chamber (Figure 7). All other measurements were done out of the climatic chamber at room conditions (stable air temperature $\mathrm{T}$ and stable wind velocities $\mathrm{v}$ ). The wind generated by propeller was directed to the hole with an embedded thermistor sensor using a short cardboard tube with honeycomb filter (as an air collimator). Therefore, outside the sensor channel the flow regime is close to laminar flow. The air flow in the wind sensor channel is laminar due to reductor with small drilled holes. 
The experimental behavior of self-heating current $I_{30}$ is given in Figures 6,7 and 8. The power dissipation $\mathrm{P}_{30}$ on the thermistor in $30^{\text {th }}$ second at constant air temperature $\mathrm{T}$ and constant voltage supply $\mathrm{U}$ consists of three components:

$$
\mathrm{P}_{30}=\mathrm{P}_{30}(0)-\Delta \mathrm{P}_{30}(\mathrm{v}, 90)-\Delta \mathrm{P}_{30}(\mathrm{v}, 90-\alpha) \ldots(4)
$$

$\mathbf{P}_{\mathbf{3 0}}(\mathbf{0})$ is power on the thermistor in the absence of wind $(\mathrm{v}=0)$ (self-heating + natural e.g. radial cooling in the channel); $\Delta \mathbf{P}_{\mathbf{3 0}}(\mathbf{v}, 90)$ is a difference between $\mathrm{P}_{30}(0)$ and $\mathrm{P}_{30}(\mathrm{v}, \alpha=90)$ (heat loss on both ends of the channel due to wind $\mathrm{v}$, angle $\alpha=90$ between wind and the main axis of the channel ); $\Delta \mathbf{P}_{\mathbf{3 0}}(\mathbf{v}, \boldsymbol{\alpha})$ is a difference between $\mathrm{P}_{30}(\mathrm{v}, \boldsymbol{\alpha}=90)$ and $\mathrm{P}_{30}(\mathrm{v}, \boldsymbol{\alpha})$ (effective axial cooling of thermistor at wind $v$ and angle $\alpha$ ): effective opening for the air flow is $S_{\text {eff }}=S \cdot \cos (90-\alpha)$, where $S$ is reductor open surface on the input of the channel. Following the self-heating current $\mathrm{I}_{30}$ at constant $\mathrm{U}$ and air temperature $\mathrm{T}$ the previous equation becomes:

$$
\mathrm{I}_{30}=\mathrm{I}_{30}(0)-\Delta \mathrm{I}_{30}(\mathrm{v}, 90)-\Delta \mathrm{I}_{30}(\mathrm{v}, 90-\alpha) \ldots \ldots(5)
$$

where $\mathrm{I}_{30}(0)$ is measured at $\mathrm{v}=0$ at constant $\mathrm{T}$ (see Figure 8, the point where all curves $I_{30}(v, 90-\alpha)$ meet together $) . I_{30}(0)$ is a function of air temperature $\mathrm{T}$ as $\mathrm{I}_{30}(0)=\mathrm{a} \cdot \mathrm{T}+\mathrm{b}$ where $\mathrm{a}$ increases with $\mathrm{T}$ slowly around 0.8 to $0.9 \mathrm{~mA} /{ }^{\circ} \mathrm{C}$ and $\mathrm{b}$ increases from 7 to $16 \mathrm{~mA}$ (Figure 6). Actually, $\mathrm{I}_{30}(\mathrm{v}, 90-\alpha)$ is a bundle of moderate concave curves (Figure 8) having analytical form as follows:

$$
\mathrm{I}_{30}(\mathrm{v}, 90-\alpha)=\mathrm{a}_{1} \mathrm{v}^{2}+\mathrm{a}_{2} \mathrm{v}+\mathrm{a}_{3} \quad \ldots \ldots(6)
$$

where $a_{1}, a_{2}$ and $a_{3}$ are a set of constants determined by computer fitting of the measured curves. The last equation (6) can be used also for interpolation of the additional calibration curves between the two neighboring calibration curves obtained by measuring. The interpolation can be done in the steps of each $0.01^{\circ} \mathrm{C}$ of the air temperature $\mathrm{T}$ as a parameter.

The wind velocity vector $\mathbf{v}$ is defined now by measuring current values of $I_{30 x}, I_{30 y}, I_{30 z}$, the current air temperature $T$ and by choosing the bundle of additional calibration curves $\mathrm{I}_{30}(\mathrm{v}, 90-\alpha)$, which corresponds to current $\mathrm{T}$. The numerical procedure of finding a common solution is similar to the graphical method shown in Figures 10, 11 and 12. In this way, the velocity vector $\mathbf{v}$ (module $|v|$, direction, and angles $\alpha$ ) is fully defined: the projections $v_{x}, v_{y}, v_{z}$ can be now calculated as $|\mathrm{v}|+\cos \left(\alpha_{\mathrm{x}}\right),|\mathrm{v}|+\cos \left(\alpha_{\mathrm{y}}\right),|\mathrm{v}|+\cos \left(\alpha_{\mathrm{z}}\right)$, respectively. The three-axis' anemometer after calibrations such as given above in section III can be oriented under compasses (X,Y), while the axis $\mathrm{Z}$ can be adjusted vertically using level.

Finally, the anemometer was tested in real conditions at $\alpha_{\mathrm{z}}=0$ in X-Y plane on the meadow in open area (placed on $2 \mathrm{~m}$ vertical rod) as in Section IV-A. The vane anemometer was used as referent. The results obtained for wind velocity in open area and in laboratory differ around $1 \%$ due to humidity and air temperature instability. The air humidity $\mathrm{H}$ is correlated with air temperature $\mathrm{T}$, so as the room humidity is often around $50 \%$ at $20^{\circ} \mathrm{C}$ [23]. The inaccuracy of humidity measurement by the humidity sensor HDC 2080 EVM was around $2 \%$ : it causes additional inaccuracy for measurement $\mathrm{I}_{30}$ but less than $0.1 \%$. The surface protection of thermistor devices from humidity was done by surface coating using thin layer of HF (high frequency) varnish. The inaccuracy of measuring U,I and R, values by digital instrumentation (Mastech R MS8221A, Fluke 179, Tektronix DMM 4040 and EA3010) was summed to the value of $0.5 \%$.

There is a small 'burden voltage' drop across the instrument in Figure 4. We intend to make a simple heat loss anemometer and used the simplest electrical measuring scheme for a practical reason: for each RCV sub-range of $10^{\circ} \mathrm{C}$ the input voltages $\mathrm{U}$ from power supply are constant.

Finally the maximum of the summed inaccuracy of our measurements with novel heat loss three-axis' anemometer do not exceed $3 \%$. The maximum of thermistor sensor sensitivity to the wind velocity $\Delta \mathrm{I} / \Delta \mathrm{v}$ is around $0.12-0.25[\mathrm{~mA}] / 1[\mathrm{~m} / \mathrm{s}]$, and repeatability of measurements of current $\mathrm{I}_{30}$ was with inaccuracy around $0.1 \%$ or less.

At the present state, the three-axis' anemometer prototype can be compared by inaccuracy and type of winds to be measured with vane-propeller anemometers [24] and hot wire heat loss anemometers [3]. The worm thermistor in pulse mode self-heating described above is used for air flow measurement; it can be used for other applications such as plant water status measurement [25].

\section{CONCLUSION}

The prototype of novel three- axis' anemometer based on the heat loss of self-heated NTC thick-film segmented thermistors measures the wind speed $\mathbf{v}$ as a vector $(\mathrm{X}, \mathrm{Y}, \mathrm{Z}$ axes) and the air temperature $T$, while humidity $H$ is measured by the commercial capacitive sensor. It operates on two principles: range constant voltage supply and power save regime (duty cycle 30s/5 min). The three-axis' anemometer system hasn't amplifiers and moving parts. In comparison to other three-axis' types, it is simpler, cheaper and easier for manufacturing, maintenance and recalibration. It is aimed for measuring the speed of stable winds with inaccuracy estimated to $3 \%$, which can be compared with the vanepropeller and hot wire anemometers. The wind speed $v$ and wind angle $\alpha$ were determined using the graphical method (current value of self-heating current and calibration curves as a function of $v$ and $\alpha$ ). The initial heat loss analysis (power dissipation) of the novel anemometer is given in the absence of wind and for the wind blow and related to heating and cooling process on the thermistor and self-heating current. The prototype can be upgraded with DACs, Bluetooth Communication, and software for processing measured data using the main and interpolated calibration curves. At the moment, the prototype developed may find use in agriculture and wind energy monitoring for windmill generators.

\section{ACKNOWLEDGMENT}

This work was supported by the Ministry for Science, Education and Technological Development of the Republic of Serbia, project TR 32016 and Institute IRITEL, Belgrade, Serbia. 


\section{REFERENCES}

[1] W. E. Knowles Middleton, Invention of the Meteorological Instruments, Johns Hopkins Press, Baltimore, 1969, pp. 3-25.

[2] S. Pindado, J. Cubas, F. Sorribes-Palmer, The Cup Anemometer, a Fundamental Meteorological Instrument for the Wind Energy Industry, Sensors, Vol.14, 2014, pp. 21418-21452.

[3] C. G. Lomas, Fundamentals of Hot-wire Anemometry, Cambridge University Press, Ch.3-Heat transfer from sensors, 1986, pp.55-83.

[4] P.Ligeza, Optimization of single-sensor two-state hot-wire anemometer transmission bandwidth, Sensors, Vol.8 (10), 2008, pp. 6747-6760.

[5] H. H. Bruun, Hot Wire Anemometry: Principles and Signal Analysis, Oxford University Press, 1995, pp. 6-19.

[6] P. Ligeza, Model and Simulation Studies of the Method for Optimization of Dynamic Properties of Tachometric Anemometers, Sensors, $2018 \mathrm{Vol}$ 18(8), 2018, pp. 2677-2689.

[7] E. Ower, R. C. Pankhurst, The Measurement of Air Flow, Ch.8-The Vane Anemometer, Pergamon Press,1977, pp.197-228.

[8] G.P.Srivastava, Surface Meteorological Instruments and Measurement Practices, Ch.5-Measurement of Surface Wind, Atlantic Publishers \&Distributors (P) Ltd., 2008, pp.180-217.

[9] D.Han,S.Kim, S.Park, Two-dimensional ultrasonic anemometer using directivity angle of an ultrasonic sensor, Microelectronics Journal, Vol.39 (10), 2008, pp.1195-1199.

[10] L.F.Riberio, Sonic Anemometer and Atmospheric Flows over Complex Terrain: Measurements of complex flows, LAP Lambert, Academic Publishing, 2012, pp.5-31.

[11] W.D. Bachalo, Experimental methods in multiphase flow, International Journal of Multiphase flow, Vol.20 (1), 1994, pp.261-295.

[12] C.Tropea, Laser Doppler anemometry: recent developments and future challenges, Measurement Science and Technology, Vol.6 (6), 1995 , pp.605 -619.

[13] S.P. Venkateshan, Mechanical Measurements, Ch. 8- Measurement of Fluid Velocity, John Wiley\& Sons, 2015, pp. 281-314.

[14] Y.H. Wang, C.Y. Lee, C.M. Chiang, A MEMS based air flow sensor with a free-standing micro-cantilever structure, Sensors 2007,Vol.7(10), pp.2389-2401.

[15] K.Kanno, N.Chiba, Development of a microphone-based wind velocity sensor and its application to real-time animation of a tree swaying in real world wind, Journal of the Society for Art and Science, Japan, Vol.6 (4), 2007, pp. 207-214

[16] H.Fujita, T.Ohhashi, M.Asakura, K.Watanabe, A thermistor anemo-meter for low flow rate measurements, Proceedings of IMTC/94-IEEE Instrumentation and Measurement Technology Conference, 10-12 May 1994, Hamamatsu, Japan,Vol.3, pp.1217-1220.

[17] J.D.Bergen, An inexpensive heated thermistor anemometer, Agricultural Meteorology, Vol.8, 1971, pp. 395-405.

[18] O.S.Aleksić, P.M.Nikolić, D. Luković, S.Savić, V.Z.Pejović, B.M. Radojčić, Thick film NTC thermistor air flow sensor", Proceedings of 24th International Conference on Microelectronics (IEEE-MIEL), May 16-19, 2004, Nis, Serbia, Vol.1, pp. 185-188.

[19] O.S.Aleksic, P.M.Nikolic, K.M.Paraskevopoulos, Volume air flow sensors based on NTC thick film segmented thermistors, Microelectronics International, Emerald ,Vol.23 (3), 2006, pp.14-18.

[20] O.S. Aleksic, M.V. Nikolic, M.D. Lukovic, N. Nikolic, B.M. Radojcic, M. Radovanovic, Z. Djuric, M. Mitric, P.M. Nikolic, Preparation and characterization of $\mathrm{Cu}$ and $\mathrm{Zn}$ modified nickel manganite NTC powders and thick film thermistors, Materials Science and Engineering B Vol.178, 2013, pp. 202-210.

[21] O.S. Aleksic, M.V. Nikolic, M.D. Lukovic, S.O. Aleksic, P.M. Nikolic, Analysis and optimization of a thermal sensor system for measuring water flow, Sensors and Actuators A: Physical Vol. 201, 2013, pp. 371- 376.

[22] J. S. Steinhart, S. R. Hart, Calibration curves for thermistors, Deep-Sea Research and Oceanographic Abstracts, Vol. 15 (4), 1968, pp.497-503.

[23] M.G. Lawrence, The Relationship between Relative Humidity and the Dewpoint Temperature in Moist Air, Bulletin of American Meteorological Society, V.ol.86, 2005, pp. 225-233.

[24] M Bujalski, M Gawor and J Sobczyk, Flow disturbance due to presence of the vane anemometer, XXI Fluid Mechanics Conference Krakow, Poland. 15 - 18 June 2014, Journal of Physics: Conference Series, IOP Publishing Vol. 530(1), 2014, 012045, pp. 1-7.

[25] J.A.Skinner, F.M.Lambert, A log-antilog analog control circuit for constant -power warm-thermistor sensors - Application to plant water status measurement, IEEE Sensors Journal, Vol. 9 (9), 2009 pp.1049-1057.

\section{Biographies of the authors:}

Stanko O. Aleksic was born on May 16, 1983. He received MSc in applied Physics at Faculty of Physics in Belgrade in 2016. He is now a research student currently working on PhD thesis in Physics of sensors at the Faculty of Technical Sciences in Cacak, University of Kragujevac. Recently he joined project with thick films thermistors in Thermo-mechanical testing and measuring laboratory in the Iritel Institute in Belgrade.

Nebojsa S. Mitrovic, member IEEE graduated at Faculty of Electrical Engineering, University of Belgrade, Serbia in 1988. He received M.Sc at Faculty of Electrical Engineering, University of Belgrade in 1993 and Ph.D in 1999 at Faculty of Technical Sciences, Cacak, and University of Kragujevac. He is currently a full time professor for Sensors: physics, principles and applications and for Physics and technology of amorphous magnetic materials at Faculty of Technical Sciences in Cacak. He published more than 100 papers and participated in 6 international projects in EU in materials research. He is member of IEEE, JMMM, EUROMAT, INTERMAG, JEMS, ISMANAM, SMM, CSMAG and SCIENCE OF SINTERING societies. His current interest is in thermal, ME, MR and MI sensors development and applications.

Zoran Nikolic graduated at the Faculty of Physices, University of Belgrade in 1994.He received a M.Sc. degree in Applied Physics in 2001 at the Faculty of Physics, University of Belgrade. He obtained a Ph.D. degree in 2006 in Applied Physics and Computer Science at the University of Belgrade. He is currently associated professor at the Faculty of Physics, University of Belgrade researching several fields in Applied Physics and Computer Science such as, fundamentals of applied physics, information systems and data bases for applications in physics. He published more than 90 papers and participated in 13 international projects in $\mathrm{EU}$ in materials research. Recently he joined few projects in scientific e-data bases at Ministry of Science and Technology Development in Belgrade.

Nina Obradovic was born on March 25, 1977 in Belgrade, Serbia. She graduated from the Faculty of Physical Chemistry, University of Belgrade, in 2001. She acquired her MSc degree at the same Faculty in 2005. Nina Obradovic was elected a Research Associate in 2005. She defended her PhD thesis at the Faculty of Physical Chemistry in Belgrade in December 2007. Nina Obradovic was elected a Research Associate in November 2008, a Senior Research Associate in March 2012 and a Principal Research Fellow in May 2017. She has been working at the Institute since 2002. She is a member of the Serbian Ceramic Society and the Society of Physical Chemists of Serbia and an Associate Editor of the journal Science of Sintering. She is is a reviewer for the Electrochemical and Solid State Letters, Processing and Application of Ceramics, International Journal of Molecular Sciences, Tehnika. Her fields of interest are: Nanostructured Materials, Powder Technology, Ceramics, Materials Characterization and Thermal Analysis.

Miloljub D. Lukovic was born on October 30, 1961. He received the B.S., M.S., and $\mathrm{Ph} . \mathrm{D}$. degrees in Electrical Engineering, all from University of Belgrade, Serbia, in 1988, 1993, and 2001 respectively. He is currently a scientific councilor at the Institute for Multidisciplinary Research. His current research interests include experimental characterization of integrated thick-film LCV cells, thick film thermistors, sensors and devices based on them and EMI suppressors.

Snezana G. Lukovic obtained her Dipl. Ing. degree at Faculty of Technology and Metallurgy in Belgrade in 1997. She joined Institute for multidisciplinary research-IMSI in Belgrade 2017 as an expert in screen printing technology and materials for paste preparation. She also worked with polymers and plastics and materials for protection of electronic components from moisture and oxidation. 